\title{
Making It Everyone's Finna - Cross-Sector Collaboration and User Experience Design in a Digital Library
}

\author{
Heli Kautonen ${ }^{1,2}$ \\ ${ }^{1}$ The National Library of Finland, Helsinki, Finland \\ heli.kautonen@helsinki.fi \\ ${ }^{2}$ Aalto University, Helsinki, Finland \\ heli.kautoneneaalto.fi
}

\begin{abstract}
This is a report on ongoing work on a digital library service focusing on user experience design. The service examined is the Finnish Digital Library, also called Finna. The service is being developed in collaboration between Finnish libraries, archives, and museums, which brings challenges and opportunities to the design of user experience. The report describes the current organizational settings of the design process by listing its actors, activities, and aims.
\end{abstract}

Keywords: User experience design, collaboration, digital libraries.

\section{Introduction}

More sophisticated information retrieval systems are needed for utilizing the material collected on the - increasingly virtual - shelves of libraries, archives, and museums (LAM). Projects carried out worldwide aim at uniting cultural heritage repositories by using different digital tools and technologies. Some of these projects reach beyond the boundaries of organization types, such as the Digital Public Library of America (DPLA), or even countries and languages, such as Europeana. ${ }^{1}$

Cross-sector digital library initiatives are usually launched because of the needs for economic efficiency and better end-user services. LAM organizations must have a strong motivation to join a deep and long-term collaboration project.

This is a report on the ongoing work on a digital library service focusing on user experience design. The report is part of an intensive case study investigating the strategic usability of a digital library service.

The service described here, namely the Finnish Digital Library, also called Finna, is exceptional in many respects. The current developments in open source software (OSS) and the agile development method alone are new to many libraries, archives, and museums in Finland. Furthermore, the development of Finna has brought the expertise of LAM sectors together in a way that no previous collaboration project has

\footnotetext{
${ }^{1}$ More information available online at $\mathrm{dp} . \mathrm{la}$ and europeana . eu. 
been able to achieve. The collaboration also covers the design and evaluation of user experience.

The idea of Finna is to serve as a national infrastructure for various types of LAM organizations in need of a user interface for their online services. In time, Finna will replace several existing interfaces. The project and the maintenance of the service are financed by the Finnish Ministry of Education and Culture. The National Library of Finland is in charge of the development of the Finna service and the OSS production, and it hosts the Finna Office.

The Finna service is based on open source software modules constituting a range of end-user interface services. The same software can be used for tailoring an interface for an individual organization's needs, but it is also the core of the national view, i.e., the basic Finna. ${ }^{2}$ At the same time, the name Finna refers to the project developing the service and uniting the Finnish LAM community in the collaboration. In this report we refer to all these various aspects of Finna.

\section{Digital Libraries and User Studies}

In the context of digital libraries, usability and user studies have been a significant area of research in the past few years. While the definition of a digital library has developed from a simple extension of the physical library into a heterogeneous set of information facilitation concepts that "cannot be captured by a simple definition" [1], the core interest in the user's preferences has remained the same.

A substantial part of research focuses on user studies: who are the users of a digital library, and what do they need from their digital service? Changes in the information environment and the consequentially evolving user needs are a challenge for digital library developers [2-4].There is also a call for stronger user involvement in design [5].

The debate on the most appropriate usability evaluation methods and usability indicators for digital libraries continues. Some researchers strongly favor the mixing of methods [6-7]. There is still a strong demand for universal instruments for this domain and attempts to develop them, e.g., [8].

Rarely do these studies on digital libraries and usability describe the organizational settings of design. It seems that practitioners and their role gain attention only if the circumstances have affected some of the challenges or solutions, e.g., [5] and [6]. Yet user experience design requires collective problem solving, as is argued by Buxton [9]. Therefore, the process and actors can be considered to be influential to the quality of the outcome, and more so when the digital library is built in collaboration.

\section{Uncovering the Activity Framework}

The organizational structure in which Finna's user experience design takes place has already changed. However, documenting its current status is important for further studies and interesting for other user experience practitioners.

\footnotetext{
${ }^{2}$ Available online at finna.fi.
} 
Finna's organizational structure can be better understood through the question: Which activity elements constitute the collaborative design of the user experience of Finna? We took an emic action research approach and carried out a thematic analysis of Finna's design process using cultural historical activity theory as a guiding framework. Activity theory has proven useful for tracking collective activities in the context of human-computer interaction and consequentially for identifying the strengths and weaknesses in a design activity [10].

The core of this report is an account of three activity components: the Actors, who currently contribute to the user experience design of Finna; the Activities conducted by the actors; and, finally, the Aims, which are either tangible or more conceptual objectives of Finna's user experience design. The account is based on proactive participant observation, i.e., our experience in working with Finna, but can also be assembled from the project documentation available on the Internet. ${ }^{3}$

\subsection{The Actors of Finna's User Experience Design}

- The in-house team at the Finna Office. The team is the central task force for conducting the usability work. It consists of interaction designers, front-end programmers, and coordinators.

- The partner organizations' implementation teams. Their role is to communicate their organization's requirements to the Finna team, and vice versa.

- The Usability Working Group. The group consists of usability experts or customer service personnel from participating organizations. The group's role is to steer the operative work, establish guidelines, and estimate future demands.

- Commercial service providers. Thus far, Finna has consulted one international and a few Finnish partners for concept analyses and visual user interface design.

- Students and researchers. Several universities in Finland have degree programs and graduate schools that focus on usability, user interaction, and user experience. Their students and researchers have made case studies of Finna.

- The OSS community. The communities that actively develop the software inevitably influence the user experience.

\subsection{The Activities of Finna's User Experience Design}

- Planning. The first task of the Usability Working Group was to make a master plan for usability work. The updated version of the Usability Plan now serves as a framework for current and future activities.

- Design and implementation. Most of the in-house team's manpower is put into design and implementation activities.

- Usability evaluation. Proper usability tests with prospective users as well as rapid user tests following the pace of agile development have been conducted.

- Tracking and analyzing actual use. Actual use is currently monitored only with one software module, which stores and analyzes the data on site traffic and visitors. Plans for qualitative surveys and usage analyses have been made.

\footnotetext{
${ }^{3}$ In English at kdk. fi/eng and in Finnish at www. kiwi.fi/display/finna.
} 
- Coordination and management. The Finna Office has been responsible for coordinating the collaboration and managing most of the activities.

- Dissemination. We have made the usability work known to the collaboration community, stakeholders, and wider audience in various presentations and publications.

\subsection{The Aims of Finna's User Experience Design}

- User interface and interaction. Although Finna utilizes OSS modules that have ready-made user interfaces and functionalities, we have modified the final end-user interfaces for our needs. The visual appearance, the layout, and the interaction elements have been and will be further redesigned.

- Integrated services. Each new integrated service alters the overall user experience and thus requires some designing or redesigning.

- Service concept. Each new partner joining Finna brings along new users and contexts of use, and therefore the service concept has to be frequently reviewed.

- End-users. With the beta version, there has been no actual use, but we have invited potential end-users to participate in testing via the contacts of the Usability Working Group and participating organizations.

\section{Challenges and Opportunities of Collaborative User Experience Design}

The analysis of Finna's current activity framework in itself cannot bring about transformation. However, reviewing it against the literature revealed some challenges and opportunities.

Examining the list of actors reveals that there is at least one potential resource that we have not involved in the design process, namely our end-users. In the context of public services, users can prove to be valuable co-designers [11]. In order to utilize the full potential of the collaboration network, the OSS community, and end-users, we should develop a strategy for how design activities can be distributed and led.

An examination of the activities indicates that our approach is still too narrow. Our current activities do not consider the flexibility or the power of open networks. The methods should also be reviewed. For example, the combination of agile software development and user experience design requires methodological awareness [12]. In the coming years of service development, we should engage in more reflection on our methods and approaches.

Reviewing the aims shows that the central element influencing the end-user experience of the service, namely the content and its representations, lacks explicit attention to its design. When partners join the project gradually over time, the process cannot be controlled as optimally as, e.g., Garrett suggests [13]. Nevertheless, Finna's contents will require design thinking.

The fact that Finna is being developed within a cross-sector community will inevitably change the mindset behind its design. All actors have to keep in mind that their design solutions will be influencing the experience of users throughout the 
collaboration network. The service will bring new users to the old services, and designers will have to consider new solutions, e.g., for ensuring accessibility.

The development phase will continue until the year 2016, but we already foresee that the user experience will require redesign as long as the service is in use. By strategically balancing the different activity components of user experience design, we aim ultimately to make Finna usable for everyone.

\section{References}

1. Candela, L. (ed.): The Digital Library Reference Model. DL.org Project Deliverable (2010)

2. Agosti, M., Crivellari, F., Di Nunzio, G.M., Gabrielli, S.: Understanding user requirements and preferences for a digital library Web portal. IJDL 11(4), 225-238 (2010)

3. Dobreva, M., Chowdhury, S.: A User-Centric Evaluation of the Europeana Digital Library. In: Chowdhury, G., Koo, C., Hunter, J. (eds.) ICADL 2010. LNCS, vol. 6102, pp. 148-157. Springer, Heidelberg (2010)

4. Khoo, M., Hall, C.: What Would 'Google' Do? Users' Mental Models of a Digital Library Search Engine. In: Zaphiris, P., Buchanan, G., Rasmussen, E., Loizides, F. (eds.) TPDL 2012. LNCS, vol. 7489, pp. 1-12. Springer, Heidelberg (2012)

5. Somerville, M., Brar, N.: A user-centered and evidence-based approach for digital library projects. The Electronic Library 27(3), 409-425 (2009)

6. Buttenfield, B.: Usability Evaluation of Digital Libraries. Science \& Technology Libraries 17(3-4), 39-59 (1999)

7. Agosti, M., Crivellari, F., Di Nunzio, G.M.: Evaluation of Digital Library Services Using Complementary Logs. In: SIGIR 2009. ACM (2009)

8. Joo, S., Lee, J.Y.: Measuring the usability of academic digital libraries: Instrument development and validation. The Electronic Library 29(4), 523-537 (2011)

9. Buxton, B.: Interactive Technologies: Sketching User Experiences. Getting the Design Right and the Right Design. Morgan Kaufmann, Burlington (2007)

10. Kaptelinin, V., Nardi, B.A.: Acting with Technology: Activity Theory and Interaction Design. MIT Press, Cambridge (2006)

11. Szebeko, D.: Case study 01: Co-Designing Services in the Public Sector. In: Meroni, A., Sangiori, D. (eds.) Design for Services, pp. 131-138. Gower Publishing, Surrey (2011)

12. Ferreira, J., Sharp, H., Robinson, H.: Agile Development and User Experience Design Integration as an Ongoing Achievement in Practice. In: Agile Conference, pp. 11-12 (2012)

13. Garrett, J.J.: The Elements of User Experience: User Centered Design for the Web. New Riders, Indianapolis (2003) 